\title{
P038. Effects of non-invasive vagus nerve stimulation on cerebral vasomotor reactivity in patients with chronic migraine during intercritical phase: a pilot study
}

\author{
Riccardo Altavilla, Matteo Paolucci, Claudia Altamura, Fabrizio Vernieri
}

From Abstracts from the 1st Joint ANIRCEF-SISC Congress

Rome, Italy. 29-31 October 2015

\section{Introduction}

Different strategies of neurostimulation have been developed as treatment tools for migraine. Among them, vagus nerve stimulation (VNS) can be performed both invasively and non-invasively. Recently, "Gammacore" has been approved as a non-pharmacological and non-invasive tool for headache, and a recent study demonstrated its efficacy in $22 \%$ of patients with acute migraine attacks [1].

Although the pathophysiology of migraine is not yet fully understood, many studies have shown a role of sterile inflammation of cerebral vessels and of the change in diameter of the intracranial arteries. Blood flow velocities and vasomotor reactivity (VMR) in patients suffering from migraine without aura in the intercritical phase were found either increased or normal compared to nonmigraineurs healthy controls [2,3]. Since the vagus nerve is the largest parasympathetic nerve of the body, it is probable that its neuromodulation can affect cerebral hemodynamics. The purpose of the study was to evaluate the effects of external vagus nerve stimulation on VMR of patients suffering from chronic migraine.

\section{Study design}

We enrolled 20 patients aged between 18 and 65 years, suffering from chronic migraine and 20 healthy nonmigraineur subjects matched for demographic characteristics. None of them assumed vaso-reactive drugs for at least 30 days before registration.

Subjects enrolled underwent registration of blood flow velocity in the middle cerebral artery bilaterally through

\footnotetext{
* Correspondence: f.vernieri@unicampus.it

Headache Centre, Neurology Unit, University Campus Bio-Medico, Rome, Italy
}

\section{Preliminary results}

No statistically significant differences emerged comparing VMR before and after VNS in our population, irrespective of groups. No patient suffered from adverse event during or after VNS.

\section{Conclusions}

Non-invasive VNS resulted safe and did not seem to influence VMR, neither in migraineurs nor in healthy volunteers. However, the small sample of our study population does not allow to draw definitive conclusions, hence the study will be further continued to extend sample size.

Written informed consent to publication was obtained from the patient(s).

\section{Published: 28 September 2015}

\section{References} noninvasive vagus nerve stimulation on acute migraine: an open-label pilot study. Cephalalgia 2014, 34(21):986-93.

2. Silvestrini M, Matteis M, Troisi E, Cupini LM, Bernardi G: Cerebrovascular reactivity in migraine with and without aura. Headache 1996, 36:37-40. 
3. Vernieri F, Tibuzzi F, Pasqualetti P, Altamura C, Palazzo P, Rossini PM, Silvestrini M: Increased cerebral vasomotor reactivity in migraine with aura: an autoregulation disorder? A transcranial Doppler and nearinfrared spectroscopy study. Cephalalgia 2008, 28:689-95.

4. Markus HS, Harrison MJ: Estimation of cerebrovascular reactivity using transcranial Doppler, including the use of breath-holding as the vasodilatory stimulus. Stroke 1992, 23:668-73.

doi:10.1186/1129-2377-16-S1-A62

Cite this article as: Altavilla et al:: P038. Effects of non-invasive vagus nerve stimulation on cerebral vasomotor reactivity in patients with chronic migraine during intercritical phase: a pilot study. The Journal of Headache and Pain 2015 16(Suppl 1):A62.

\section{Submit your manuscript to a SpringerOpen ${ }^{\mathcal{O}}$ journal and benefit from:}

- Convenient online submission

- Rigorous peer review

- Immediate publication on acceptance

- Open access: articles freely available online

- High visibility within the field

- Retaining the copyright to your article

Submit your next manuscript at $\gg$ springeropen.com 